Revista Iberoamericana, Vol. LXXIX, Núm. 243, Abril-Junio 2013, 465-477

\title{
TRAVESÍAS BAILABLES: REVISIÓN HISTÓRICA EN LA MÚSICA DE RITA INDIANA HERNÁNDEZ
}

\author{
POR \\ LORNA TORRADO \\ The University of Texas at Austin \\ “...people danced in the streets to merengues \\ denouncing the fallen dictator" \\ Paul Austerlitz, Merengue: Dominican Music and \\ Dominican Identity \\ “...intercalamos risa y llanto, gustos y sustos, \\ dolores y tambores, bachata y rap, \\ aquí y allá” \\ Josefina Báez, Dominicanish
}

Rita Indiana Hernández (1977) es una escritora, performera y cantante dominicana. Aunque fue criada en la República Dominicana, sus constantes viajes y estadías en Puerto Rico y los Estados Unidos han influido considerablemente en su trabajo y en su conexión con la comunidad diaspórica. Tanto sus textos literarios como su música abordan temas como la dictadura dominicana, la migración y el racismo. Su abierta homosexualidad y su estética andrógina forman parte de su propuesta contestataria hacia la ideología patriarcal heteronormativa dominicana, convirtiéndola en un ícono cultural para la comunidad lésbica tanto en el Caribe hispano como en la comunidad transnacional.

Hasta el momento, el estudio académico de la obra de Hernández se ha centrado primordialmente en sus dos novelas La estrategia de Chochueca (2000) y Papi (2005). Especialistas del campo como Néstor E. Rodríguez, Juan Duchesne-Winter y Myrna García-Calderón exaltan el tono cínico con el que la literatura de Hernández se enfrenta a la historia oficial dominicana, su ambiciosa propuesta de una nueva narrativa nacional y la formulación de un sujeto dominicano contemporáneo. Sólo Celiany Rivera-Velázquez, en su ensayo "The Importance of Being Rita Indiana-Hernández: Women-Centered Video, Sound, and Performance Interventions within Spanish Caribbean Cultural Studies", discute varios de los trabajos performáticos de la artista dominicana y de qué manera su androginia articula una multiplicidad de formas convencionales y alternativas 
de cómo ser una mujer dominicana y caribeña. ${ }^{1}$ Sin embargo, su disco compacto $E l$ Juidero (2010) y sus videos musicales aún no han sido analizados como parte de su crítica a los vestigios del trujillato. Este aparato ideológico, impuesto durante las tres décadas del gobierno de Rafael Leonidas Trujillo (1930-1961) y extendido por Joaquín Balaguer (1966-1978), edifica la identidad nacional a través de la heteronormatividad, la inmovilidad geográfica y el antihaitianismo. ${ }^{2}$ Críticos como Frank Moya Pons, Deborah Pacini-Hernández, Juan Otero-Garabís, Paul Austerlitz, entre otros, han enfatizado la centralidad del merengue dentro de esta maquinaria ideológica para la construcción de una identidad nacional. Frente a esta tradición homogenizadora, Hernández se reapropia de esta música como artefacto contestatario del estatus quo dominicano. ${ }^{3}$

El Juidero es el primer disco compacto de larga duración de la agrupación Rita Indiana y Los Misterios. Las canciones abarcan temas sobre la dictadura e identidad dominicana, la experiencia migratoria y la desigualdad social. Rítmicamente el trabajo también es variado al fusionar ritmos caribeños y latinoamericanos como el merengue rápido, el mambo, la salsa y la balada, entre otros. Esta integración de ritmos es importante ya que, como menciona Hernández en una entrevista con la revista digital 80 grados: "el merengue de calle y el mambo violento se instalaron en la República Dominicana como intento de ruptura con el acartonamiento acomplejado que dejó el trujillismo y el balaguerato" (Rodríguez Saavedra). Por otro lado, tal fusión refleja la experiencia transnacional de Hernández y el uso de la música como espacio en el cual mantener lazos con el país de origen y simultáneamente incorporar las tendencias del país anfitrión. El concepto de transnacionalidad que manejo es definido por Jorge Duany como "the construction of dense social fields across national borders as a result of the circulation of people, ideas, practices, money, goods, and information" ("Los países" 32). Gracias a su capacidad de desplazamiento la música funciona dentro de esta red de intercambio social como herramienta contradiscursiva al incorporar a la diáspora como parte del cuerpo nacional.

Aunque el discurso identitario dominicano ha rechazado sistemáticamente la incorporación de la comunidad diaspórica como parte del colectivo nacional, la historia de la República Dominicana puede ser trazada como una serie de huidas, traslados y regresos. En su libro El retorno de las yolas: ensayos sobre diáspora, democracia y

1 En el artículo titulado "Visual Storytelling: Cinematic Ekphrasis in the Latin American Novel of Globalization”, Dierdra Reber discute varias obras literarias latinoamericanas, entre ellas La estrategia de Chochueca, de Hernández enfocándose en cómo el texto puede ser leído como una serie de espectáculos en movimiento.

2 El antihaitianismo es un término usado por el crítico Ernesto Sagás en su artículo "A Case of Mistaken Identity: Antihaitianismo in Dominican Culture" para referirse al rechazo sistemático de todo "lo haitiano" como base del discurso de identidad dominicana.

3 Para más información sobre el papel que jugó el merengue durante el régimen trujillista, véase Julie A. Sellers.

Revista Iberoamericana, Vol. LXXIX, Núm. 243, Abril-Junio 2013, $465-477$
ISSN 0034-9631 (Impreso) 
dominicanidad, Silvio Torres-Saillant destaca la centralidad de los éxodos dominicanos desde las primeras décadas de la colonia (durante la segunda mitad del siglo xvI), hasta el período republicano (a mediados del siglo xIx) como parte esencial de la historia de la isla. Para las clases dirigentes del país, estas primeras olas migratorias han sido vistas como grandes pérdidas culturales por tratarse de dominicanos pudientes y en su mayoría blancos. Por el contrario, los éxodos de la segunda mitad del siglo xx fueron percibidos de manera positiva por tratarse de afrodominicanos pobres, despreciados como sobrantes de la nación (31-34). La música de Hernández rescata el movimiento migratorio como eje histórico vertiendo la isla fuera de sus contornos geográficos y convocando el regreso de los que se han ido de la República Dominicana. Rita Indiana ejemplifica lo que Torres-Saillant denomina "el retorno de las yolas" ya que desde la diáspora propone un "potencial para ayudar a modificar los parámetros conceptuales vigentes en el discurso sobre la dominicanidad" (38).

Tomando en cuenta el vacío crítico sobre el trabajo musical de Hernández, analizo la forma en que la artista reescribe musicalmente la historia dominicana contemporánea a través del movimiento migratorio. Este sujeto dominicano rítmico rechaza la narrativa identitaria impuesta por la ideología trujillista para reinventarse a través de una identidad queer y transnacional. Utilizo el término queer como una práctica liminal de desafío que pone en tela de juicio las categorías patriarcales a través del rechazo sistemático de la primacía heteronormativa. En adición, tomo en cuenta las implicaciones transnacionales discutidas por Larry La Fountain-Stokes, en su libro Queer Ricans: Cultures and Sexualities in the Diaspora, cuando señala: "The word 'queer' itself carries a very specific charge of disruption; its use signifies the reappropriation of an insult and its transformation into something new and different” (xi). De modo que a través de la práctica liminal de sus personajes musicales, Hernández transforma y resignifica la dominicanidad contemporánea.

Partiendo de la rearticulación de un sujeto dominicano contemporáneo cabe preguntarse: ¿De qué forma se constituye una identidad basada en el movimiento, en la violencia histórica y en la experiencia de la migración?, y ¿ ¿ómo es representado el cuerpo nacional en los videos de Hernández para romper con el ideal trujillista? Como sugiere el título de la compilación, El Juidero, sustantivo derivado del verbo "huir", la experiencia migratoria del sujeto dominicano funciona como hilo conductor del disco. La foto de la portada es una ilustración temática al presentar a Rita Indiana dentro de un carro en marcha y a los integrantes de la banda en poses que sugieren desplazamiento, mientras sus miradas huyen fuera del marco resistiéndose al lente fotográfico que intenta inmovilizarlos. Me acercaré específicamente a cuatro canciones y a sus respectivos videos como coordenadas de un mismo relato que revisita varios momentos fundamentales de la historia dominicana para desarticular el discurso oficial.

El tema musical "Da Pa Lo Do" revisa el discurso fundacional nacional basado en el antihaitianismo. El título, formalmente pronunciado da para los dos, captura el

\footnotetext{
Revista Iberoamericana, Vol. LXXIX, Núm. 243, Abril-Junio 2013, 465-477 ISSN 0034-9631 (Impreso) 
lenguaje coloquial del Caribe hispano, mientras inyecta un tono infantil a través de la brevedad silábica y la repetición vocálica. Sin embargo, la temática está muy lejos de ser un mero juego de niños al presentar una visión crítica y recriminatoria de la separación física e ideológica entre la Republica Dominicana y Haití:

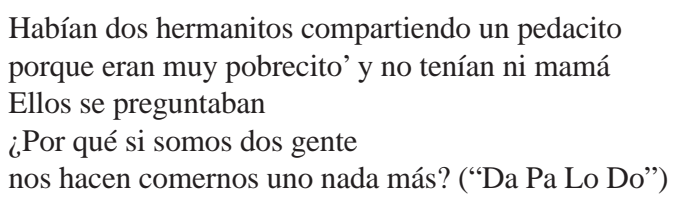

A través de la rencilla infantil Hernández invoca la violenta historia de lucha y separación entre los dos países hermanos que aún forzados a compartir la misma isla tienen un largo historial de confrontación, fomentado, en gran parte, por el Estado dominicano. La ocupación y dominación haitiana durante veintidós años (1821-1844) produjo un discurso identitario que "definió los contornos de una nación castiza, hispanófila y católica que se oponía a la supuesta 'barbarie' representada por el Estado haitiano” (Rodríguez, La isla 4). A lo largo del siglo xx los regímenes paternalistas de Trujillo y Balaguer promovieron una narrativa centrada eficazmente en la negación de la herencia afrodominicana, vista como elemento ajeno a los pilares nacionales. Como señala Dawn F. Stinchcomb en su libro The Development of Literary Blackness in the Dominican Republic, esta ficción fue instrumentalizada para inventar un "país de blancos”(8). El rechazo de todo lo "negro", trunca el desarrollo de una identificación con lo afrodominicano y simultáneamente difunde el sentimiento antihaitiano hasta hoy. Desafiando la autoridad de las voces patriarcales de los dirigentes e intelectuales dominicanos que construyeron la plataforma ideológica que sostiene la idea de separación entre los dos países, Hernández asume la voz del padre en la canción para regañar a los dos hermanos:

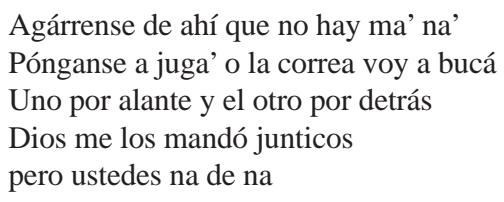

Estas líneas muestran la imposibilidad histórica de lograr una reconciliación, teniendo como resultado la intervención del padre en un intento por terminar la rencilla. Rita Indiana lleva a cabo un gesto de travestismo lírico al asumir la voz del padre y la figura autoritaria masculina asociada con los mandatos de Trujillo y Balaguer. De esta forma desarticula la autoridad histórica basada en el patriarcado y el autoritarismo.

Revista Iberoamericana, Vol. LXXIX, Núm. 243, Abril-Junio 2013, $465-477$
ISSN 0034-9631 (Impreso) 
En adición, la cantante expone el uso de la violencia física durante estos regímenes al amenazar a los dos hermanos con "la correa" si no se comportan. Es importante destacar la burla que encierra este gesto ya que los jefes de estado usaban la violencia a favor de la desunión y la separación de ambos países, mientras que aquí el castigo será impuesto si no hay reconciliación. Al sacar a la luz esta contradicción, Hernández ridiculiza el discurso oficial del patriarcado y desenmascara la irracionalidad infantil de la doctrina trujillista basada en el "mito fundacional” antihaitiano.

Paralelamente, la metáfora de los dos hermanos le permite a la cantante revisar el discurso racial dominicano que abiertamente ignora las raíces y herencia africana. La voz del padre les recuerda que ambos comparten el mismo origen colonial y por consiguiente, la herencia racial:

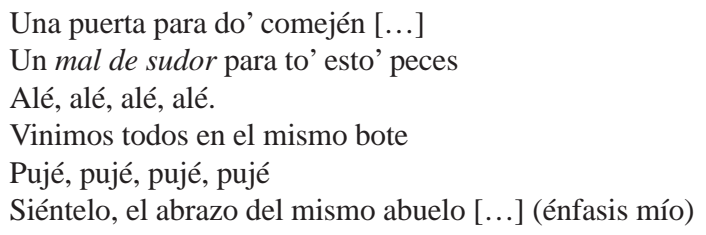

Estas líneas desafían el mito fundacional dominicano al identificar el origen nacional en las raíces africanas. Todos son hijos de la macrohistoria del choque colonial y nietos del sudor, trabajo y explotación de los esclavos africanos. Es fundamental el juego de significados que Hernández provoca con la palabra “mal”, que bien puede leerse como “mar”o “mal” debido a la pronunciación caribeña. Esta dualidad abre dos posibilidades de lectura, por un lado el verso “mal de sudor para to’ esto’ peces” recupera el parto trágico y violento del Caribe como producto de la conquista, la colonización y la esclavitud. Por otro lado, la lectura de esta línea usando la palabra “mar” acentúa la hermandad geográfica que comparten ambos países al formar parte de una sola isla, así como la imposibilidad de huir del conflicto ideológico que aún los separa. El "mar” no sólo los contiene, sino que como han estudiado Yolanda Martínez-San Miguel, Frances Aparicio y Jorge Duany, entre otros, los une con el resto del Caribe. Esta cercanía los define como sujetos transnacionales al habitar espacios intersticiales entre la tierra de origen y el país en donde se vive. Consciente de la discriminación contra las comunidades dominicanas en el extranjero y aprovechando el travestismo lírico de la voz narrativa, Hernández encara al dominicano con la realidad migratoria caribeña: "Si es que ellos ‘tan bien aquí/ aunque tú no seas de ahí /¿tú no tiene doce tíos en otro país? [...]”. Con estas líneas la cantante les recuerda a sus compatriotas que además de compartir la herencia africana con los haitianos, habitan lo que Mary Louise Pratt denomina “zona de contacto”, para referirse al espacio común donde personas de diferentes nacionalidades establecen

\footnotetext{
Revista Iberoamericana, Vol. LXXIX, Núm. 243, Abril-Junio 2013, 465-477 ISSN 0034-9631 (Impreso) 
relaciones que muchas veces envuelven condiciones de conflicto y desigualdad (6).

La canción finaliza con un llamado a la reconciliación y, como toda fábula infantil, con un mensaje didáctico:

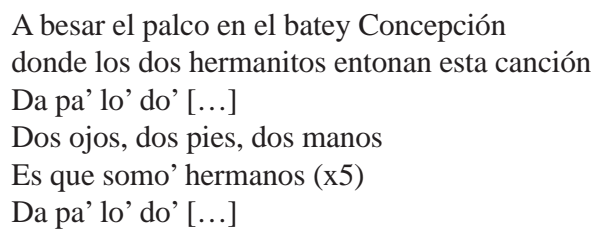

Reiterando nuevamente el legado afrodominicano a través de la mención del batey, espacio vinculado a la producción de caña de azúcar, Rita Indiana Hernández reconcilia ambas naciones haciendo uso de la herencia africana como denominador común. Así, esta primera coordenada histórica articula un nuevo sujeto dominicano producto de la migración colonial. Luego de darse cuenta de que son parte de una misma geografía y corporalidad, tanto literal como simbólica, los dos hermanos están preparados para enfrentar su realidad juntos porque "da pa' lo do".

Dejando establecido la centralidad diaspórica en la identidad dominicana, Hernández revisita la violenta realidad de los sucesos políticos del siglo xx. Del cuestionamiento e infantilización del mito identitario, pasamos a un mundo saturado por la corrupción y la violencia política en el mambo violento de "El Juidero". Aunque en el artículo "No podía presentar algo wimpy, ¡eso es violencia!”, Hernández asocia esta canción con los años de la presidencia de Balaguer, analizo la letra y las imágenes del video como colapso de una misma narrativa dictatorial basada en la violencia, la represión y la corrupción estatal que produce la huida acelerada del personaje:

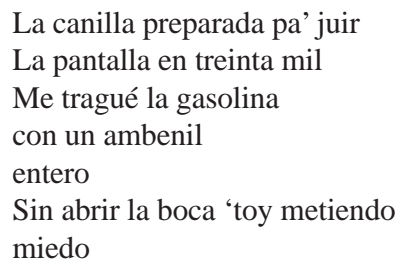

La falta de transparencia en relación a la causa de la huida alude a las políticas represivas y la imposibilidad de hablar abiertamente durante los regímenes de Trujillo y Balaguer. Esta ambigüedad discursiva continúa con la idea de poder "meter miedo" sin tener que pronunciar una palabra, frase que no solo alude a la censura estatal, sino que también se refiere a las prácticas no convencionales de comunicación desarrolladas por la ciudadanía y los grupos subversivos para burlarla.

Revista Iberoamericana, Vol. LXXIX, Núm. 243, Abril-Junio 2013, $465-477$
ISSN 0034-9631 (Impreso) 
La desesperación por escapar de la República Dominicana es reforzada musicalmente por el ritmo acelerado que rompe de manera simbólica con el "sonido oficial” y exclusivo del merengue cibaeño y "blanqueado" del trujillato. Así mismo, la repetición incesante del coro funciona como el ruido premonitor de una alarma que anuncia la salida en masa: “Éxodo/ voy pa’ Puelto Rico/ Éxodo/ Má' lejo’ que Egipto”. Aquí la voz lírica asume una identidad colectiva y el personaje dominicano joven de "Da Pa Lo Do" se transmuta en este "ya crecido" cuerpo dominicano que retoma el movimiento para escapar del país. Este éxodo encapsula simbólicamente las diferentes oleadas migratorias dominicanas producto de los conflictos políticos y económicos de la segunda mitad del siglo xx. Así, en esta segunda revisión histórica, la identidad dominicana es articulada como una construcción "en tránsito", fluida y transnacional.

El video musical de "El Juidero" añade complejidad a la historia abriendo nuevos espacios interpretativos. Usando la estética del blaxploitation afroamericano de los años setenta, la directora puertorriqueña Noelia Quintero-Herencia relata la historia de un grupo de malhechores que trafica armas en la República Dominicana. Nuevamente el video juega con la falta de transparencia y no sabemos si los personajes son un grupo de revolucionarios o son una reinterpretación de La Banda Colorá, ${ }^{4}$ un grupo antiterrorista y anticomunista, contratado por Balaguer durante su tercera presidencia (1966-1978) para reprimir a la izquierda dominicana. Tomando en consideración la letra de la canción y la historia del video musical formulo las siguientes preguntas: ¿cómo se construye visualmente el "dominicano”? y ¿̇de qué forma se desafía la idea tradicional de dominicanidad con la reinterpretación de este momento histórico?

El personaje de la sicaria, interpretado por Hernández, figura como una afrenta simbólica contra las concepciones patriarcales del trujillato perpetuadas por el gobierno de Balaguer. Su apariencia andrógina, llevando el pelo muy corto y ropa masculina, dialoga con la performatividad del drag king definida por Pendleton-Jiménez como el acto de vestirse temporalmente de forma masculina para crear un espacio liminal que descubre la falsedad de las categorías de género (260). El entorno lleno de armas y violencia también forma parte de su masculinización y entrada simbólica en el espacio violento de los regímenes autoritarios. Partiendo de la idea del cuerpo del drag king como lugar de cuestionamiento, la sicaria se convierte en escenario liminal desde donde se cuestiona la heteronormatividad y se articula una subjetividad dominicana queer

4 La idea de un grupo de matones que aterroriza a la población no es nada nuevo en la historia de la República Dominicana. Sellers comenta en su libro: “A cornerstone of Trujillo’s repressive tactics was La 42, a group of terrorists that he had formed during his presidential campaign. La 42's sole purpose was to coerce the Dominican population with violence and terror” (90). Luego Trujillo creó el SIM en 1957: "[...] an intricate spy network, the Servicio de Inteligensia Militar (Miliary Intelligence Service) [...]” (90). Específicamente sobre los actos terroristas de La Banda, Sellers señala: "Over 3000 Dominicans died in terrorist acts between 1966 and 1974. Balaguer claimed he had nothing to do with La Banda and that the government had attempted to control de group without success” (119).

Revista Iberoamericana, Vol. LXXIX, Núm. 243, Abril-Junio 2013, $465-477$
ISSN 0034-9631 (Impreso) 
como práctica de resistencia ante la ideología nacional. También, su juego de chaqueta y pantalón rojo no sólo apunta hacia su indefinición genérica sino que evoca de forma literal a La Banda Colorá y toda la sangre dominicana derramada por la represión y violencia del trujillismo y el balaguerato.

El movimiento como elemento contestatario contra el imaginario de ambos regímenes se refleja en el baile cuya coreografía remite al éxodo como liberación simbólica del cuerpo nacional. Como mencioné anteriormente, el merengue fue instrumento de control del pueblo dominicano, y el baile extendió el poder estatal directamente sobre los cuerpos. En "El Juidero", por el contrario, el baile se despoja de la narrativa oficial para presentarse como un performance liberador. Dalila Rodríguez Saavedra comenta que la coreografía del video se basa en la "traducción de un baile de Yemayá -deidad protectora asociada con el mar y la maternidad. [...][Hay] una mezcla de tai chi, disciplinas contemporáneas y de la tradición yoruba que simboliza, entre otras cosas el mar que protege a los miles de yoleros que cruzan el Caribe" ("No podía”). Por lo tanto la coreografía del bailarín dominicano Vicente Santos articula un espacio maternal que rechaza y descentra la violenta masculinidad patriarcal. Con la reapropiación del baile, el cuerpo como espacio contestatario de los regímenes autoritarios logra liberarse del momento histórico y procede a huir hacia la isla de Puerto Rico bajo la protección de la deidad afrodominicana.

La tercera reescritura histórica ocurre con la canción "Pásame a bucá”, una versión moderna del cuento infantil de "La Cenicienta" que engloba las diferentes olas migratorias de la República Dominicana a Puerto Rico. Olas que comenzaron en la década de los sesenta, luego del asesinato de Trujillo, y continúan hasta hoy como producto de los altibajos de la economía dominicana. Yolanda Martínez-San Miguel y Jorge Duany han estudiado cómo la diáspora dominicana es sistemáticamente marginalizada por la sociedad puertorriqueña. Los factores principales para este rechazo son su condición de indocumentados, la falta de recursos económicos y sus rasgos afrodominicanos. Este perfil basado en estereotipos y prejuicios de clase y raza los coloca en la periferia del imaginario socio-racial puertorriqueño (Duany, "Between the Nation” 461).

A diferencia del ritmo rápido de "El Juidero”, este tema comienza lento, evocando el uso del bolero como género más íntimo para relatar historias de corte personal:

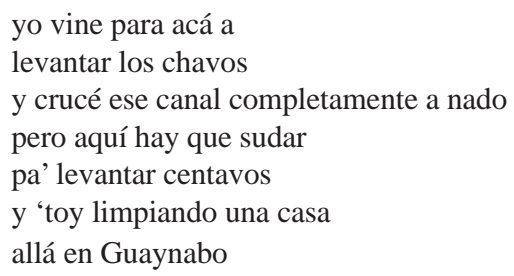

Revista Iberoamericana, Vol. LXXIX, Núm. 243, Abril-Junio 2013,
ISSN 0034-9631 (Impreso) 
Estas líneas hacen referencia a la dura realidad laboral que experimenta la empleada doméstica dominicana en Puerto Rico. El paralelo entre la canción de Hernández y el clásico cuento de hadas de la Cenicienta es evidente cuando describe a la familia para la cual trabaja:

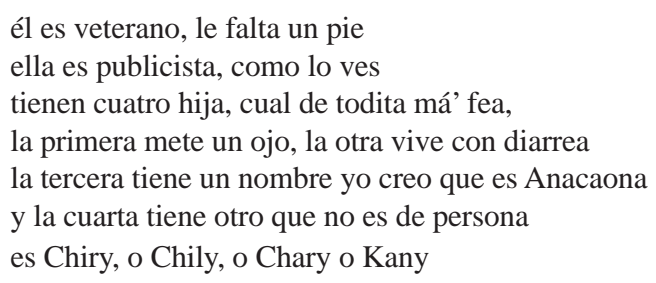

La violencia de la exclusión social es interpelada por la voz narrativa a través de la ridiculización y animalización de las “hermanastras” feas y defectuosas. Este gesto, típico de las historias infantiles para resaltar los valores morales del protagonista, es emulado por Hernández para rebajar a los que disfrutan de mayor poder social, elevando así la calidad humana de la empleada doméstica. Sin embargo, esta Cenicienta dominicana no es tan sumisa como el personaje del cuento de hadas y su agresividad lingüística se traduce en violencia corporal:

[...] se me quieren subí' arriba porque soy dominicana cuando lo papá no miran yo le doy macana cuando salgo de esa casa la sangre me hierve $[\ldots]$

Así mismo, el silencio denunciado en "El Juidero" como consecuencia de la represión balaguerista se rompe y la queja ante los sufrimientos y las injusticias sufridas por el éxodo se escucha claramente. Es ahora el dominicano el que se convierte en "el otro" y es visto como un "problema" para la sociedad puertorriqueña. Este cambio de perspectiva funciona como metáfora de la multiplicidad de los procesos demarginalización y racialización que se metamorfosean y reproducen en el Caribe como producto de los movimientos migratorios y las estructuras de poder locales.

"Pásame a bucá" trastoca el centro y la periferia al narrar la historia desde la perspectiva del inmigrante indocumentado. La Cenicienta encuentra a su príncipe azul, también inmigrante, y le pide que la pase a buscar para salir de fiesta:

pásame a bucá' en la bicicleta tuya

como la de Eduardo que

no haga bulla

pásame a bucá' en el mercedes de tu abuela

Revista Iberoamericana, Vol. LXXIX, Núm. 243, Abril-Junio 2013, $465-477$
ISSN 2154-4794 (Electrónico) 


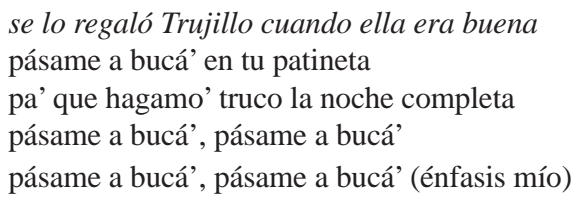

Una vez fuera del trabajo, la chica disfruta de su "libertad". Sin embargo, aun cuando ha logrado escapar de la situación de su país, el pasado la persigue en su travesía transnacional a través de la figura de Trujillo con la mención del "mercedes de la abuela". Precisamente es el recuerdo de corrupción, presente en “El Juidero”, el que nuevamente se plasma en estos versos como fantasma de la historia oficial del trujillismo y del balaguerato. Dentro de este panorama, Hernández mantiene una actitud positiva, a tono con los cuentos de hadas, por haber sobrevivido el peligroso trayecto hasta Puerto Rico:

que aunque eto' boricua quieran acabar conmigo

hay que celebrar que llegamo’ vivo

que el mar no me chupó, que somo’ do’, tú y yo

que llegando a Mayagüez, los tiburones me dijeron que

tú me estabas esperando [...]

El sujeto dominicano en movimiento enfrenta la violencia migratoria e institucional, mientras continúa en una constante negociación identitaria.

La última coordenada dentro de la reescritura de la historia dominicana, "La hora de volvé", relata el paso del dominicano a suelo norteamericano y la obligatoria negociación identitaria ante la otredad, producto del sistema racial del vecino del norte. El video musical presenta a Rita Indiana y a sus bailarines en un colorido planeta lleno de volcanes, lava y extrañas criaturas. El astro que estéticamente conmemora la obra surrealista La persistencia de la memoria (1931) de Salvador Dalí, representa la tierra extranjera, foránea e inhóspita. Transitarla requiere maña, porque hay volcanes votando lava y escupiendo piedras por todos lados. La canción es narrada en segunda persona con un tono recriminatorio una vez que se ha pasado por la cruda realidad diaspórica en "Pásame a bucá":

[...] en otro país es a comer basura rusa

Te la buscaste como todo un león

hiciste tanta fuerza que te quedó un cuarto de cojón

Pegaste botones y pega hasta con la boca

Y le aguantaste vainas a toditas la 'aquerosa'

Súbite nevera con 5 vaca a’ entro

Y un inverno en Nueva Yol te vite muelto

Revista Iberoamericana, Vol. LXXIX, Núm. 243, Abril-Junio 2013,
ISSN 2154-4794 (Electrónico) 
Caía la nieve sobre el cuerpo adolmecido

Tenías hasta los intestinos entumecidos [...]

Haciendo uso del humor se describe la fría realidad del inmigrante caribeño en Estados Unidos para deconstruir el discurso utópico del "sueño americano". Similar a la empleada doméstica en Puerto Rico, el sujeto dominicano se ha sometido a todos los trabajos imaginables para lograr sobrevivir. La experiencia migratoria se presenta como una emasculación simbólica al referirse a la misma como una pérdida de "cojones", área masculina que popularmente se asocia con la valentía y la hombría tradicional latinoamericana. Entonces, el sujeto dominicano resulta "herido" en la "batalla" de la migración y se ve forzado a dejar a un lado el machismo propio de la masculinidad heteronormativa.

El viaje que se emprendió por la búsqueda de oportunidades se convierte en una historia de desencanto y ya es hora de regresar a la República Dominicana:

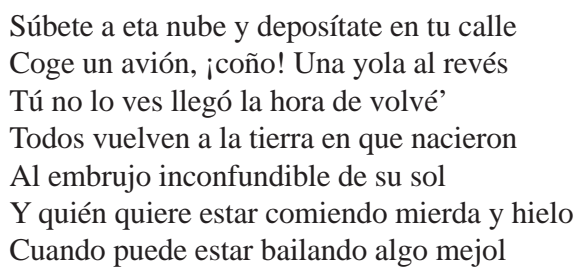

La travesía de desplazamiento comenzada en "El Juidero" también termina en baile, ahora ejecutado en la otra dirección. En contraste con los brazos usados como remos en el video de "El Juidero" ahora éstos se extienden como alas del avión de regreso. Esta idea de retorno como alternativa superior a la vida en los Estados Unidos supone un cambio respecto al imaginario convencional en el que se ve aquel país como tierra de oportunidades. Sin embargo, aun cuando el video termina con estas imágenes celebratorias, la realidad del que regresa está muy lejos de ser una fiesta, ya que tiene que enfrentarse al rechazo y a la racialización de sus compatriotas. El retorno resulta un límite capaz de mostrar las fisuras producidas por la emigración en los discursos supuestamente coherentes de la nacionalidad. En la narrativa musicalizada de Hernández el regreso se presenta como un final abierto lleno de posibilidades frente a las realidades del sujeto dominicano en constante movimiento.

Como hemos visto a través de este ensayo, la propuesta musical de Hernández, análoga a su producción literaria, plantea la articulación de una dominicanidad contemporánea que rompe con los patrones identitarios basados en la ideología trujillista. Hernández problematiza los procesos de otredad y marginalización como producto de los movimientos diaspóricos caribeños. Sus canciones articulan un sujeto

\footnotetext{
Revista Iberoamericana, Vol. LXXIX, Núm. 243, Abril-Junio 2013, 465-477 ISSN 0034-9631 (Impreso) 
afrodominicano transnacional queer que deja a un lado las ideas de blanqueamiento y heteronormatividad. El valiente taíno Enriquillo es destronado como padre e imagen del mito fundacional nacional para ser sustituido por el éxodo africano producto de la historia colonial. De esta forma, el dominicano simbólico se redibuja desde lo negro y su proximidad al cuerpo nacional haitiano. Asimismo, éste se presenta en un estado de constante metamorfosis y adaptación como producto de los desplazamientos, resaltando la realidad diaspórica dentro de la historia dominicana. La violencia de la ideología dictatorial también propicia una nueva transformación dentro del siempre cambiante sujeto dominicano que utiliza la androginia como espacio queer para rechazar y burlarse de los discursos del patriarcado.

La propuesta final del regreso a la isla no figura como una conclusión definitiva y mucho menos utópica, sino que recalca las tensiones que surgen de estos desplazamientos cuando chocan con ideologías nacionalistas excluyentes y estáticas que no logran absorber la realidad de sus sujetos en constante cambio y movimiento. Hernández apunta hacia la imposibilidad de capturar una identidad dominicana unidimensional y llama la atención sobre la necesidad de rearticular al sujeto contemporáneo desde la multiplicidad de sus experiencias históricas.

\section{OBRAS CITADAS}

Aparicio, Frances R., y Cándida Frances Jáquez. Musical Migrations. Basingstoke: Palgrave Macmillan, 2003.

Austerlitz, Paul. Merengue: Dominican Music and Dominican Identity. Philadelphia: Temple UP, 1997.

Báez, Josefina. Dominicanish: a Performance Text. Nueva York: Josefina Báez, 2000.

Duany, Jorge. "Between the Nation and the Diaspora: Migration to and from Puerto Rico.” Desde la orilla: hacia una nacionalidad sin desalojos. Silvio Torres-Saillant, Ramona Hernández y Blas R. Jiménez, comps. Santo Domingo: Manatí; Librería La Trinitaria, 2004. 449-68.

"Los países: Transnational Migration from the Dominican Republic to the United States.” Dominican Migration: Transnational Perspectives. Ernesto Sagás y Sintia Molina, eds. Gainesville: UP of Florida, 2004. 29-52.

Duchesne-Winter, Juan. "La profecía, espectáculo e interrupción en Rita Indiana Hernández”. Revista de Crítica Literaria Latinoamericana 67 (2008): 289-308.

García-Calderón, Myrna. "Current Approaches to Hispanic Caribbean Writing: An Overview.” Review: Literature and Arts of the Americas 40/1 (2007): 61-72.

Hernández, Rita Indiana. La estrategia de Chochueca. San Juan: Isla Negra Editores, 2003. Papi. San Juan: Ediciones Vértigo, 2005.

La Fountain-Stokes, Lawrence M. Queer Ricans: Cultures and Sexualities in the Diaspora. Minneapolis: U of Minnesota P, 2009.

\footnotetext{
Revista Iberoamericana, Vol. LXXIX, Núm. 243, Abril-Junio 2013, $465-477$
ISSN 0034-9631 (Impreso)
} 
Martínez-San Miguel, Yolanda. Caribe Two Ways: cultura de migración en el Caribe Insular hispánico. San Juan: Ediciones Callejón, 2003.

Moya, Pons Frank. The Dominican Republic: a National History. Princeton: Markus Wiener, 2010.

Otero, Garabís Juan. Nación y ritmo: “descargas” desde el Caribe. San Juan: Ediciones Callejón, 2000.

Pacini, Hernandez Deborah. Oye Como Va!: Hybridity and Identity in Latino Popular Music. Philadelphia: Temple UP, 2009.

Pendleton-Jimenez, Karleen. "From Tomboy to Drag: Las notas de un rey in Toronto.” 28th Annual Conference Proceedings. National Association for Chicana and Chicano Studies Annual Conference. San Jose State University, 2001. 257-64.

Pratt, Mary Louise. Imperial Eyes: Travel Writing and Transculturation. Londres: Routledge, 1992.

Reber, Dierdra. "Visual Storytelling: Cinematic Ekphrasis in the Latin American Novel of Globalization.” Novel: A Forum on Fiction 43/1 (2010): 65-71.

Rita Indiana y los Misterios. “Da Pa Lo Do”. El Juidero. Premium Latin Music, Inc., 2010. “El Juidero”. El Juidero. Premium Latin Music, Inc., 2010.

"La hora de volvé”. El Juidero. Premium Latin Music, Inc., 2010.

"Pásame a bucá”. El Juidero. Premium Latin Music, Inc., 2010.

Rivera-Velázquez, Celiany. “The Importance of Being Rita Indiana-Hernández: WomenCentered Video,Sound, and Performance Interventions within Spanish Caribbean Cultural Studies." Globalizing Cultural Studies: Intersections in Communications and Culture: Global Approaches and Transdisciplinary Perspectives. Cameron McCarthy et al., eds. Nueva York: Peter Lang, 2007. 205-227.

Rodríguez, Néstor E. La isla y su envés: representaciones de lo nacional en el ensayo dominicano contemporáneo. San Juan: Editorial Instituto de Cultura Puertorriqueña, 2003.

Rodríguez Saavedra, Dalila. "No podía presentar algo wimpy, jeso es violencia!” 80 Grados. 12 Nov. 2010. <http://www.80grados.net>. 7 ago. 2012.

Sagás, Ernesto. "Haiti: Antihaitianismo in Dominican Culture.” Webster University. Web. 30 Oct. 2011.<http://www.webster.edu/ corbetre/haiti/misctopic/dominican/ antihaiti.htm>.

Sellers, JulieA. Merengue and Dominican Identity: Music as National Unifier. Jefferson, N.C.: McFarland \& Co., 2004.

Stinchcomb, Dawn F. The Development of Literary Blackness in the Dominican Republic. Gainesville: UP of Florida, 2004.

Torres-Saillant, Silvio. El retorno de las yolas: ensayos sobre diáspora, democracia y dominicanidad. Santo Domingo: Librería La Trinitaria; Editora Manatí, 1999.

Revista Iberoamericana, Vol. LXXIX, Núm. 243, Abril-Junio 2013, $465-477$
ISSN 2154-4794 (Electrónico) 
